\title{
Особенность вещественного состава и специализация габбро- анортозитовых массивов Дальневосточного пояса на титановые и медно-никелевые руды
}

\author{
Копылов М.И., Тихомирова А.И. \\ Институт тектоники и геофизики ИТиГ ДВО РАН, Хабаровск, Mishil.Kopa@таil.ru
}

Аннотация. В работе рассмотрены и обобщены материалы региональных и крупномасштабных геолого-геофизических работ АО «Дальгеофизика», ИТиГ и др. в пределах габбро-анортозитовых массивов Дальневосточного пояса. По результатам этих исследований определены особенности глубинного строения габбро-анортозитовых массивов и закономерности размещения в пределах их титановой, медно-никелевой, фосфорной и ванадиевой минерализаций. Приводятся описание наиболее перспективных медно-никелевых и титановых рудопроявлений и месторождений.

Ключевые слова: габбро-анортозитовые массивы, титановые, медно-никелевые руды, месторождения, рудопроявления.

\section{Mineralogical composition and specialization of the gabbro-anorthosite massifs of the Far Eastern belt for titanium and copper-nickel ores}

\section{Kopylov M.I., Tikhomirova A.I.}

Institute of Tectonics and Geophysics, Khabarovsk, Far Eastern Branch, Russian Academy of Sciences, Mishil.Kopa@mail.ru

Abstract. The paper reviews and summarizes the data from regional and large-scale geological and geophysical studies of the Far Eastern gabbro-anorthosite belt carried out by JSC "Dalgeofizika", ITiG, and others, which helped to define the deep structure of the gabbro-anorthosite massifs and the patterns in the distribution of titanium, coppernickel, phosphorus, and vanadium mineralization in them. The copper-nickel and titanium ore occurrences and deposits indicating the highest economic potential are described.

Key words: gabbro-anorthosite massifs, titanium, copper-nickel ores, deposits, ore occurrences.

\section{Введение}

Металлогеническая специализация магматических комплексов во многом определяется составом родоначальных расплавов и режимом их дифференциации. Сульфидное $\mathrm{Cu}-\mathrm{Ni}$ оруденение в базитовых расслоенных массивах приурочено главным образом к сравнительно магнезиальным породам ранней стадии кристаллизации, что следует из известного геохимического поведения никеля и коллекторных свойств сульфидных фаз в отношении халькофильных элементов. Развитию сульфидного оруденения благоприятствует также пониженная щелочность расплава, что можно оценить по коэффициенту агпаитности - $\left(\mathrm{K}_{2} \mathrm{O}+\mathrm{Na}_{2} \mathrm{O}\right) / \mathrm{AL}_{2} \mathrm{O}_{3}$, пониженные значения которого способствуют сульфуризации расплава. Известно также, что никеленосные комплексы характеризуются преимущественно «боуэновским» трендом дифференциации. Для анортозитовых же массивов с характерными железо-титановыми проявлениями свойственен «феннеровский» тип с абсолютным и относительным накоплением железа, что обусловлено фракционированием в больших объемах плагиоклаза и, в меньшей мере, пироксенов при сравнительно низком окислительном потенциале (Ленников А.М., 1979).

\section{Модели образования медно-никелевых месторождений}

Относительно механизма образования медно-никелевых месторождений существуют несколько моделей, из них наиболее значимы метасоматическая и ликвационная. По метасоматической модели происходит оливинизация пород с образованием мономинеральных оливинитов и мономинеральных медно-никелевых руд внутри оливинитов. Химизм процесса заключается в выносе из пироксенитов железа и привносе магния. Процесс происходит в твердом субстрате за счет ион- 


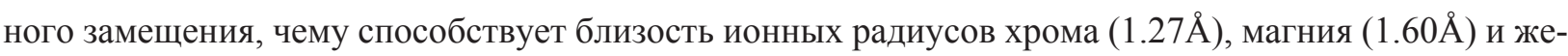

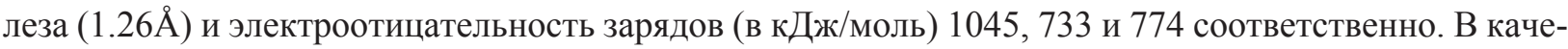
стве источника меди и никеля выступают ультраосновные породы, но, вероятно, часть металла привносится ювенильными растворами вместе с магнием.

При рассмотрении ликвационной модели месторождений, связанных с дифференцированными интрузиями основного и ультраосновного состава, выявляются месторождения сульфидные, медно-никелевые и медно-никелево-платиновые. Месторождения этого типа встречаются сравнительно редко, но для них характерно однообразие геологических условий образования и состав руд. Генезис этих месторождений довольно сложный и не всегда однозначно относимый к ликвационному типу. Примером таких месторождений могут служить Норильское, Таланахское, Октябрьское, из зарубежных: Садбери и Томсон в Канаде, район Бушвельда в Южной Африке и Кун-Маньё на юге Дальнего Востока.

По агпаитности все габбро-анортозитовые массивы Дальневосточного региона имеют величину коэффициента агпаитности $\left(\mathrm{K}_{\mathrm{a}}\right)$ меньше единицы и относятся по этому признаку к миаскитовой группе. Это указывает, что ход кристаллизации магматического раствора происходил, когда сиалические минералы (полевые штаты, фельштатоиды) выделялись раньше, чем мафические (метасиликаты, слюды и др.). Наиболее низкими значениями коэффициента агпаитности характеризуются Лантарский, Баладекский и Брянтинские массивы (Баженова Г.Н., 1964; Копылов М.И., 2009). Для Сехтагского и Чогарского массивов характерен узкий диапазон значений $\mathrm{K}_{\mathrm{a}}$, это указывает, что их образование происходило в стабильной обстановки при выдержанном количестве щелочей и глинозема. Геранский и Куранахский массивы, напротив, формировались в длительный период времени и часто меняющихся обстановках, на что указывает широкий диапазон изменений коэффициента агпаитности от 0.05 до 0.5

\section{Медно-никелевая минерализация в пределах габбро-анортозитовых массивов}

В Лантарском габбро-анортозитовом массиве, выявленные рудопроявления меди, никеля и кобальта с включением платиновой группы минералов расположенные в его северной эндоконтактовой части (рис. 1). Лантарский массив является крайним (восточный фланг) в полосе базитультрабазитовых массивов, окаймляющих с юга древнейшие кристаллические образования Алданского щита Сибирской платформы. На рудопроявлении Няндоми кроме меди и никеля установлены содержание платины и палладия, в рудах Авланджинского и Одоринского рудопроявлений определена платина. Рудопроявление Одоринское залегает в горизонте пегматоидных габбро, габброноритовой зоны, рудопроявление Авланджинское-в горизонте пегматоидных анортозитов. Кроме пирротина руды содержат 3-5 \% халькопирита, пентландит, пирит, марказит, висмутин, магнетит, титаномагнетит, ильменит, гидроокислы железа. Из минералов платиновой группы определены мончеит, сперрилит, котульскит, платино-палладиевый теллуро-висмутит. Работами ФГУП «Дальгеофизика» (с участием автора) и старательской артели «Восток» 1997-2000 гг. завершено изучение поверхности рудопроявлений, оценены ресурсы меди, никеля, платиноидов. Рудопроявление Няндоми по данным проведенных горных работ и опробования полотна канав и расчисток представлены сульфидизированными горизонтами. Рудопроявление приурочивается к подошвенной части горизонта представленного базитовыми разностями. Рудные интервалы имеют видимую мощность от 0.5 до 25 м со средним содержанием меди 0.22-1.01 \%, никеля 0.17-0.54 \%, кобальта 0.022-0.13 \%. Кроме того, в рудных интервалах установлено наличие платины до 4.94 г/т, палладия до 2.6 г/т, золота до 1.78 г/т.

В пределах рудопроявление Контактовое выделяется одноименная зона, изученная детальными исследованиями в интервале более 2.5 км. В пределах изученной части зоны общая суммарная длина аномальных полос (горизонтов), фиксируемых ореолами меди, никеля, кобальта, превышает 5000 м. В пробах из эпицентров геохимических аномалий, содержания золота и платины составляют 0.01-0.06 г/т и 0.01-0.98 г/т соответственно. По результатам опробования канав и скважин, среднее содержание компонентов во вкрапленных сульфидах зоны Контактовой составляют: нике- 


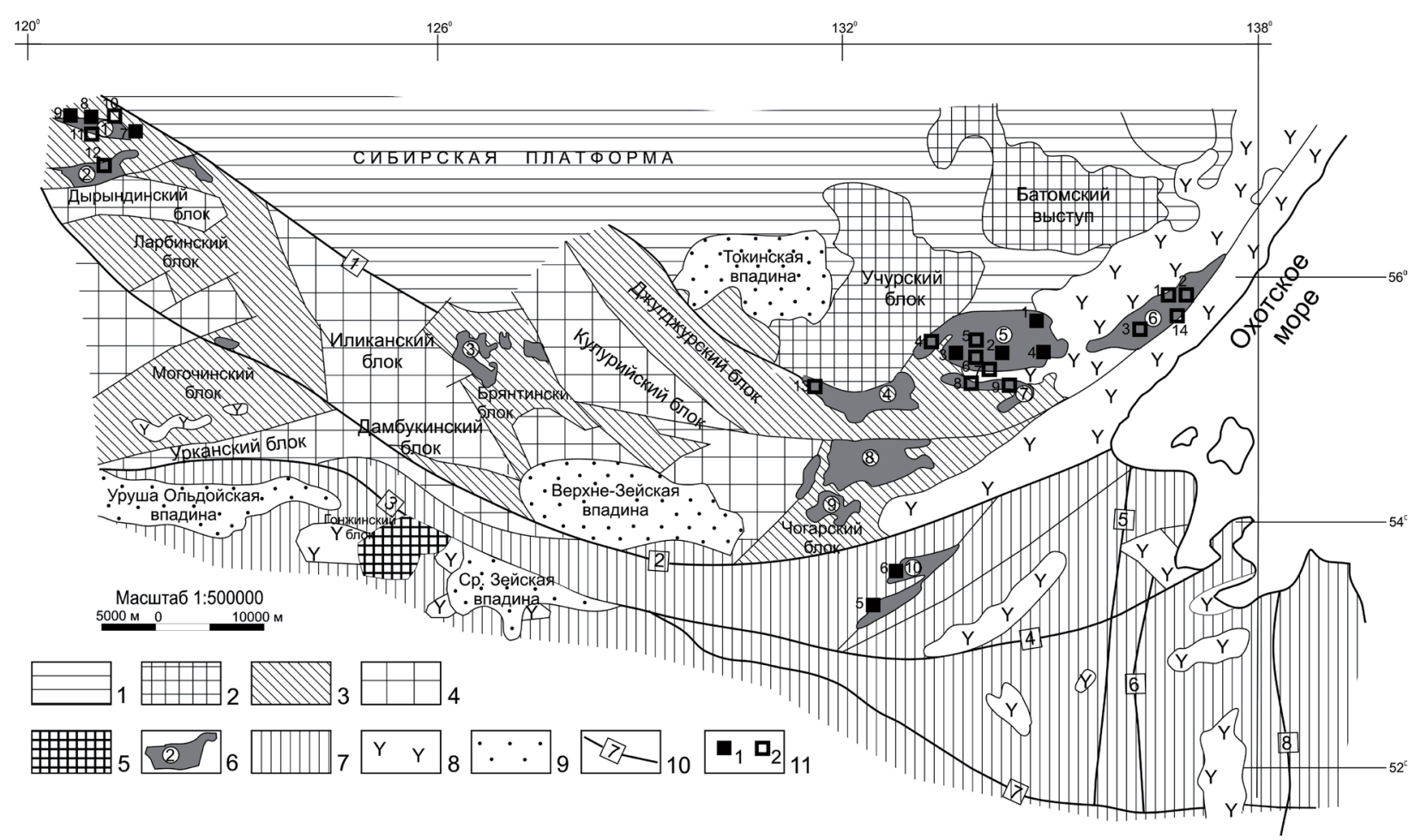

Рис. 1. Структурная позиция Восточно-Азиатского анортозитового пояса на схеме докембрийской тектоники Сибири и Дальнего Востока.

1 - Сибирская платформа; 2-5 - архейские гнейсы и кристаллические сланцы: 2 - нижнего архея (Алданский Щит), 3 - нижнего и 4 - верхнего архея (Становая складчатая область), 5 - докембрийского возраста; 6 - габбро-анортозитовые (с выходами ультраосновных пород) и их названия: 1 - Куранахский, 2 - Брянтинский, 3 - Кун-Маньенский, 5 - Геранский, 6 - Лантарский, 7 - Джанинский, 8 - Сегтахский, 9 - Чогарский, 10 - Баладекский; 7 - Монголо-Охотская ГСС; 8 - вулканиты (J-К); 9 - современные впадины; 10 - основные тектонические нарушения и их названия: 1 - Становой, 2 - Северо-Тугурингрский, 3 - Южно-Тугурингрский; 4 - Тугурский, 5 - Торомский, 6 - Нимеленский, 7 - Пауканский, 8 - Центрально-Сихотэ-Алинский; 11 - месторождения титана (1): 1 - Геранское, 2 - Гаюмское, 3 - Богидэ, 4 - Маймаканское, 5 - Урожайное, 6 - Двавакит, 7 - Б. Сейим, 8 - Саикта, 9 - Куранах; рудопроявления (2): 1 - Муддакинда, 2 - Лантарское, 3 - Мутэхское, 4 - Усомахское, 5 - Правобережное, 6 - Сорогнское, 7 - Сололинское, 8 - Сахарбинское, 9 - Джанинское, 10 - Балтылах, 11 - Водораздельное; 12 - Имангаитское: медно-никелевые, 13 - Соболевское, 14 - Нянди.

Fig. 1. Schematic map of the Precambrian tectonics of Siberia and the Far East of Russia showing structural position of the East Asian anorthosite belt.

1 - Siberian Platform; 2-5 - Archean gneisses and crystalline schists: 2 - Lower Archean (Aldan Shield), 3 - Lower and 4 - Upper Archean (Stanovaya folded area), 5 - Precambrian age; 6 - gabbro-anorthosite (with ultrabasic rock outcrops) and their names: 1 - Kuranakhsky, 2 - Bryantinsky, 3 - Kun-Manyonsky, 5 - Geransky, 6 - Lantarsky, 7 - Dzhaninsky, 8 - Segtakhsky, 9 - Chogarsky, 10 - Baladeksky; 7 - Mongolo-Okhotsk GSS; 8 - volcanic rocks (J-K); 9 - present-day depressions; 10 - main faults and their names: 1 - Stanovoy, 2 - North-Tuguringrsky, 3 - South-Tuguringrsky; 4 - Tugursky, 5 - Toromsky, 6 - Nimelensky, 7 - Paukansky, 8 - Central-Sikhote-Alinsky, 11 - titanium deposits (1): 1 - Geranskoye, 2 - Gayumskoye, 3 - Bogide, 4 - Maimakanskoye, 5 - Urozhainoye, 6 - Dvavakit, 7 - Bolshoy Seyim, 8 - Saikta, 9 - Kuranakh; ore occurrences (2): 1 - Muddakinda, 2 - Lantarskoye, 3 - Mutekh, 4 - Usomakh, 5 - Pravoberezhnoye, 6 - Sorognskoye, 7 - Sololinskoye, 8 - Sakharbinskoye, 9 - Dzhaninskoye, 10 - Baltylakh, 11 - Vodorazdelnoye; 12 - Imangaitskoye: copper-nickel, 13 - Sobolevskoye, 14 - Nyandi.

ля $0.11 \%$, меди $0.212 \%$, кобальта $0.039 \%$, платиноидов 0.17 г/т, золота 0.01-0.08 г/т, серебра 1-6 г/т. В массивных пирротиновых рудах содержание никеля составляет 0.5-0.6 \%, меди 0.5-3.0 \%, кобальта до $0.2 \%$. Средняя суммарная мощность рудоносных интервалов в каждом из 3 сечений по скважинам составила $7.3 \mathrm{M}$. 
Рудопроявление Пирротиновое представлено одноименной зоной, которая выделяется разноориентированными фрагментами горизонта вкрапленных и массивных сульфидных руд, выведенных на дневную поверхность в зоне разломов северо-восточного направления, протяженность ее около 1.5 км, ширина 0.7 км. Мощность массивных руд составляет 2.6 м.

Массивные руды-существенно пирротиновые с халькопиритом и пентландитом, гнездами и полосами грязно-зеленого волоарита. Содержание рудных элементов в среднем (на площадь руд-

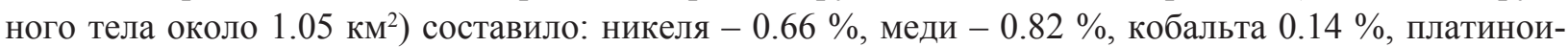
дов -1.63 г/т.

Рудопроявления Озерное, Авланджинское, Одоринское-1, Одоринское-2 выделяются в пределах нижнего рудоносного горизонта ранее проведенными работами в интервале 1750 м, представлены линзами сплошных пирротиновых руд размерами от первых метров до $50 \times 40$ м. Эти параметры определяют только видимый выход рудного тела, т.к. в промежутках между линзами отмечаются интенсивные ореолы меди, никеля и кобальта. Массив Кунь-Маньё располагается на юго-восточной окраине Алдано-Станового щита Сибирской платформы. Здесь в последние годы поисковыми и поисково-оценочными работами силами ФГУГП «Дальгеофизика» (с участием одного из авторов) была выявлена серия рудоносных структур и рудопроявлений с медно-никелевой минерализацией промышленного типа.

Ареал распространения рудных и рудоносных тел мафит-ультрамафитов кун-маньёнского комплекса, по данным поисковых работ, выделяется в ранге рудного узла. Пространственно этот ареал приурочен к юго-западной краевой части Кун-Маньёнского массива раннеархейских метагабброидов майско-джанинского комплекса, на отдельных участках - к вмещающим его метаморфитам джанинской серии зоны экзоконтакта. Рудные и рудоносные тела мафит-ультрамафитов следятся в виде роя в полосе шириной 1-2 км, протягивающегося в северо-западном направлении на протяжении 14 км. Фрагментарно эта рудоносная зона прослежена поисковыми маршрутами и гравиметрической съемкой на северо-запад за пределы рудного узла Кун-Маньё на 40 км.

В пределах рудного узла выявлено около 30 крупных и десятки мелких интрузий мафитультрамафитов, расположенных группами, часто в несколько ярусов, реже отмечаются одиночные разрозненные тела. Породы этого рудоносного комплекса представлены вебстеритами, плагиовебстеритами (габбро-норитами), гарцбургитами, лерцолитами, клино- и ортопироксенитами, горнблендитами, верлитами. Наиболее широко среди них распространены вебстериты и плагиовебстериты. Они слагают в основном полого падающие на северо-восток и север, плитообразные и линзовидные тела мощностью от 0.1-1 м до 70-80 м и протяженностью от 50 м до 1-3 км, и лишь в редких случаях - круто падающие маломощные (до 1 м) и непротяженные линзовидно-инъекционной формы жилы.

Кроме охарактеризованных габбро-анортозитовых и базит-гипербазитовых массивов несущих медно-никелевую минерализации в промышленных масштабах в пределах восточной части Дальневосточного пояса, в его центральной и западной частях существуют ряд более мелких массивов (Лучанский, Лукиндинский, Ильдеусский, Гетканский, Уркиминский, Хорогочинский, Брянтинский, Ильдеусский, Маристый, Кенгуракский) перспективных на выявление медно-никелевой минерализации с повышенным содержанием платиноидов и золота.

\section{Титановая, фосфорная и ванадиевая минерализация в габбро-анортозитоых массивах}

В пределах габбро-анортозитовых массивов Дальневосточного пояса комплексными геологогеофизическими исследованиями изучены более 50 рудопроявлений и четыре крупных месторождения апатито-титановых руд. Среди них выделено четыре генетических типа: раннемагматический, позднемагматический, метаморфический и метасоматический (Беляев Е.В. и др., 1981) минерализации. К раннемагматическому типу относится крупное месторождения Богидэ и ряд проявлений локализованных в краевой фации Геранского массива, в основании и верхней части расслоенной серии. Рудные тела имеют пластообразную, реже линзовидную формы и залегают соглас- 
но с вмещающими габброидами, имея с ними постепенные переходы. Рудная зона, вмещающая месторождение Богидэ, прослежена по данным магниторазведки и горными выработками на протяжении более 10 км. Строение зоны неоднородное, на северо-западном фланге и в ее центральной части руды представлены вкрапленным типом апатит-титановых руд со средними содержаниями $\mathrm{P}_{2} \mathrm{O}_{5}(3.4-4.5 \%)$ и $\mathrm{TiO}_{2}(3.5-5.5 \%)$, которые чередуются с рядовыми рудами $\mathrm{P}_{2} \mathrm{O}_{5}(5.3-6.4 \%)$ и $\mathrm{TiO}_{2}$ (6.5-8.5 \%). Мощности тел, слагающих зону, изменяются от 10 до 80 м при протяженности от 400 до 3000 м. Среди богатовкрапленных руд встречаются линзообразные тела массивных ильмениттитаномагнетит-апатитовых руд с высокими содержаниями $\mathrm{P}_{2} \mathrm{O}_{5}(8-10 \%)$ и $\mathrm{TiO}_{2}(10.8-17.1 \%)$.

Каларский габбро-анортозитовый массив относится к типу андезиновых (Беляев Е.В. и др., 1981). По данным гравитационного и магнитного полей он является фрагментом одного крупного плутона, разделенного зонами гранитизации и блоковой тектоники. Сохранилась центральная часть этого плутона в виде Куранахского массива площадью более 1500 кв.км. По данным детальных геолого-геофизических исследований отмечаются постепенные переходы между фациями, в анортозитах в сторону краевой фации увеличивается количество шлировых обособлений габбро, габброноритов и они приобретают линейные формы и в краевой фации следует ритмичное чередование слоев анортозитов, габбро, габбро-анортозитов, габбро-норитов. В пределах Куранахского массива по аэромагнитной и наземной магнитометрической съемках выявлено более 25 титано-железистых рудопроявлений, два мелких месторождения Куранахское, Саиктинское и уникальное месторождение Большой Сэйим (Копылов М.И., 2009). В геологическом строении этого уникального месторождения принимают участие образования позднеархейского габбро-анортозитового комплекca, формирование которого происходило в три последовательные фазы. Магнетит-ильменитовое оруденение пространственно и генетически связано с формированием второй фазы, представленной роговообманковыми оливин-гранатсодержащими метагабброидами и ультрамафитами. Месторождение Большой Сэйим по геолого-геофизическим данным представлено единым штокообразным телом, выходы которого на дневную поверхность близки к подковообразной форме. При оконтуривании по борту $5 \% \mathrm{TiO}_{2}$ рудное тело разделяется на две зоны: Восточную и Западную. Восточная зона представляет собой крутопадающую линзовидную залежь. Содержания $\mathrm{TiO}_{2}$ по сечениям меняются от 7.31 до 11.48 \% при среднем содержании $8.45 \%$, железа общего $17.98 \%$, железа магнетитового $9.73 \%, \mathrm{~V}_{2} \mathrm{O}_{5}-0.1 \%, \mathrm{P}_{2} \mathrm{O}_{5}-1.4 \%$.

Западная зона в морфологическом отношении представляет собой крутопадающую залежь с падением на Ю3 под углами 75-85. Протяженность зоны-550 м., мощность её изменяется от 180 м до 379 м и в среднем равна 220 м. Средние содержания $\mathrm{TiO}_{2}$ в сечениях изменяются от 7.02 до $10.67 \%$ и в среднем составляют $8.32 \%$, железа общего $17.73 \%$, железа магнетитового - $3.58 \%$; $\mathrm{V}_{2} \mathrm{O}_{5}-0.1 \%$; $\mathrm{P}_{2} \mathrm{O}_{5}-1.03 \%$.

Обсуждение результатов выполненных исследований. Приведенные данные геологогеофизических исследований Дальневосточного анортозитового пояса показали, что при сходном вещественном и минералогическом составов они несут разную минерализацию. Одни массивы несут руды халькофильно-сидорофильной $(\mathrm{Cu}, \mathrm{Ni}, \mathrm{Co}, \mathrm{Ti}, \mathrm{Au}, \mathrm{Pt})$, другие литофильной $(\mathrm{P}, \mathrm{Ti}, \mathrm{V}, \mathrm{Cr}$, $\mathrm{Mn}, \mathrm{Zr}$ ) групп и рассеянных $\mathrm{Sc}, \mathrm{Y}, \mathrm{Nb}$ элементов. Раннемагматические руды локализованы чаще всего в образованиях краевой фации, в основании расслоенных анортозитовых массивов и верхних частях на границе с анортозитами центральной фации. Позднемагматические залежи концентрируются в большей степени в образованиях центральной анортозитовой фации в области ее сочленения с расслоенными габброидами краевой фации.

На Геранском массиве преобладает ильменит-титаномагнетит-апатитовые руды, а на Сехтагском, Каларском массивах - магнетит-ильменитовые руды, несмотря на отнесение их к одному андезитовому типу. Возможно, это связано с разной степенью эрозионного среза, а также различной интенсивностью метаморфических преобразований. Последний процесс способствует также изменению минерального и вещественного состава руд. Перекристаллизация и старение структур распада способствует разделению титаномагнетита на две самостоятельные фазы-ильменитовую и магнетитовую. Высокотемпературный метаморфизм руд связан преимущественно с процессами грани- 
тизации, где происходит вынос более подвижного железа и концентраций геохимически инертного титана и облагораживание руд. В связи с этим на промышленно титано-магнетитовое оруденение более перспективными являются анортозитовые массивы и их части, которые претерпели интенсивную гранитизацию.

\section{Литература}

1. Баженова Г.Н. Геологическое положение и строение Каларского анортозитового массива. Геология и геофизика. 1964. № 11.

2. Беляев Е.В., Панских Е.А., Файзулин Р.М., Роганов Г.В., Гаврилов В.В. Минерагеническая специализация и перспективная оценка Джугджуро-Становой апатитоносной провинции // Геология и геофизика. 1981. № 12. C. 55-63.

3. Копылов М.И. Прогнозно-поисковые признаки и критерии титановых и медно-никелевых месторождений в пределах Дальневосточного габбро-анортозитового пояса // Руды и металлы. 2009. № 4. С. 45-56.

4. Ленников А.М. Анортозиты юга Алданского щита и его складчатого обрамления. М. Наука. 1979. С. 10-21. 